\title{
THE SUMMER MEETING AT WILLIAMSTOWN
}

The fortieth summer meeting and seventeenth colloquium of the Society was held at Williams College, Williamstown, Massachusetts, from Tuesday to Friday, September 4-7, 1934. The meeting was preceded by that of the Mathematical Association of America. About two hundred seventy persons attended the meetings, among whom were the following one hundred sixtynine members of the Society:

C. R. Adams, R. B. Adams, R. P. Agnew, E. B. Allen, D. B. Ames, R. C. Archibald, R. P. Bailey, D. H. Ballou, R. A. Beaver, A. A. Bennett, Theodore Bennett, William Beverley, Harry Birchenough, Garrett Birkhoff, G. D. Birkhoff, L. M. Blumenthal, Joseph Bowden, J. W. Bower, H. W. Brinkmann, B. H. Brown, H. S. Brown, R. E. Bruce, J. A. Bullard, L. H. Bunyan, W. H. Bussey, S. S. Cairns, W. D. Cairns, R. H. Cameron, B. H. Camp, C. C. Camp, G. A. Campbell, F. E. Carr, W. B. Carver, Abraham Cohen, L. W. Cohen, H. R. Cooley, L. P. Copeland, Byron Cosby, M. J. Cox, H. B. Curry, D. R. Curtiss, J. H. Curtiss, H. H. Dalaker, D. R. Davis, F. F. Decker, L. L. Dines, H. A. DoBell, H. L. Dorwart, Jesse Douglas, Arnold Dresden, L. A. Dye, H. T. Engstrom, G. W. Evans, H. P. Evans, H. S. Everett, O. J. Farrell, D. A. Flanders, L. R. Ford, W. B. Ford, R. M. Foster, C. W. Franklin, Philip Franklin, T. C. Fry, A. S. Galbraith, C. A. Garabedian, H. M. Gehman, J. J. Gergen, B. P. Gill, D. C. Gillespie, J. G. Hardy, Alan Hazeltine, O. C. Hazlett, E. R. Hedrick, M. R. Hestenes, T. R. Hollcroft, E. V. Huntington, W. A. Hurwitz, J. I. Hutchinson, M. H. Ingraham, R. L. Jeffery, B. W. Jones, L. S. Kennison, B. F. Kimball, J. R. Kline, H. L. Krall, J. H. Kusner, W. D. Lambert, A. E. Landry, R. E. Langer, V. S. Lawrence, A. M. M. Lehr, Harry Levy, Hans Lewy, E. R. Lorch, N. H. McCoy, W. H. McEwen, L. A. MacColl, Saunders MacLane, Morris Marden, A. E. Meder, G. M. Merriman, H. J. Miles, E. C. Molina, C. N. Moore, Richard Morris, Marston Morse, David Moskovitz, E. J. Moulton, J. R. Musselman, D. S. Nathan, J. H. Neelley, E. P. Northrop, C. O. Oakley, Oystein Ore, F. W. Owens, H. B. Owens, F. W. Perkins, H. B. Phillips, Hillel Poritsky, G. B. Price, Tibor Rado, S. M. Rambo, O. J. Ramler, J. F. Randolph, W. R. Ransom, H. W. Raudenbush, M. S. Rees, W. T. Reid, C. E. Rhodes, R. G. D. Richardson, D. E. Richmond, Robin Robinson, W. E. Roth, H. G. Russell, S. A. Schelkunoff, C. E. Seely, I. M. Sheffer, J. A. Shohat, L. L. Silverman, W. G. Simon, T. M. Simpson, M. M. Slotnick, A. W. Smith, C. E. Smith, W. M. Smith, Virgil Snyder, E. S. Sokolnikoff, I. S. Sokolnikoff, A. H. Sprague, E. C. Stokes, M. M. Sullivan, T. Y. Thomas, J. I. Tracey, F. E. Ulrich, J. L. Walsh, L. E. Ward, J. F. Wardwell, A. C. Washburne, C. W. Watkeys, M. S. Webster, V. H. Wells, H. S. White, Hassler Whitney, Norbert Wiener, A. H. Wilson, E. W. Wilson, R. G. Wood, E. R. Worthington, C. H. Yeaton. 
The colloquium lectures, on Fourier transforms in the complex domain, as originally planned by Professor Norbert Wiener and Dr. R. E. A. C. Paley (now deceased) were delivered on Tuesday afternoon and Wednesday, Thursday, and Friday mornings. These lectures, which were attended by eighty-nine members of the Society, will appear in book form as volume 19 of the Colloquium Publications of this Society.

By invitation of the Committee on Program, Professor J. A. Shohat gave on Thursday afternoon an address entitled On the expansion of functions in series of orthogonal polynomials.

Wednesday afternoon was devoted to an excursion over the Taconic Trail to the new Bennington College for Women and Bennington battlefield. An interesting account of the battle of Bennington was given by $\mathrm{Mr}$. W. C. Hart, a lineal descendant of one of the leaders in this engagement. On Wednesday evening Dr. and Mrs. Charles Louis Safford gave a very fine organ and song recital in Chapin Hall; Dr. Safford is the organist of Williams College.

On Thursday evening a joint dinner of the Society and the Mathematical Association of America was held at the Greylock Hotel. Professor E. V. Huntington acted as toastmaster and called upon President Tyler Dennett of Williams College, on Professor E. R. Hedrick representing the Society, and on President Arnold Dresden of the Association. Professor Virgil Snyder presented a resolution expressing appreciation of the cordial hospitality of the College. He called attention to the fact that this was the second time that the Society had held its summer meeting at Williamstown, the first occasion having been in 1905. Seven members present had attended the earlier meeting and recalled it with pleasure.

At the close of the colloquium on Thursday morning a group photograph of those in attendance was taken. The American Mathematical Monthly expects to reproduce this photograph.

The dormitories of Williams College were open to members and their guests. A delightful social center was furnished through the generosity of the Governors of the Faculty Club who extended its privileges to the members of the group. Here the ladies of the Department of Mathematics of Williams College served tea every afternoon. The college tennis courts were avail- 
able free of charge and the Taconic Golf Club offered reduced rates to members of the Society.

The Council met on the evening of September 4 th and various actions taken at this time were reported to the Society.

The following twelve persons were elected to membership in the Society:

Mr. Carliton Eugene Buell, Washington University;

Mr. John Hamilton Curtiss, Harvard University;

Professor Emmet Roach Elliott, Hampden-Sidney College;

Mr. Henry Gerhardt, Mobile, Alabama;

Mr. John Pawl Gill, Jr., University of Alabama;

Mr. Paul Matthew Hummel, Ohio State University;

Dr. Louis Kattsoff, University of Virginia;

Dr. Ellis R. Ott, University of Buffalo;

Mr. Billy James Pettis, Brown University;

Mr. Walter Stevens Turpin, Johns Hopkins University;

Dr. George Cuthbert Webber, University of Chicago;

As nominee on the Sustaining Membership of the Western and Southern Life Insurance Company: Mr. Richard James Learson, Jr.

It was reported that in accordance with a reciprocity agreement, the following person has joined the Society;

Professor C. Wilhelm Oseen, Nobelinstitutet, Stockholm, Sweden.

The Secretary announced the election of the following persons to membership by mail vote of the Council since its meeting in April:

Dr. John Henry Augustus Brahtz, U.S. Bureau of Reclamation, Denver, Colorado;

Professor Raymond Donald Douglass, Massachusetts Institute of Technology;

Dr. Kurt Gödel, Princeton University;

Professor Harriette Grace Holt, University of Wisconsin Extension;

Professor O. M. Lind, Ch'an Cheng-Lob' Philosophical Centre, Thaton, Burma;

Mr. Vicente Mills, Department of Agriculture and Commerce, Manila, Philippine Islands;

Dr. Daniel T. Sigley, University of Kansas City;

Professor John H. Van Vleck, University of Wisconsin;

Dr. Stefan Emanuel Warschawski, Columbia University;

Professor Earl Francis Watts, Massachusetts Institute of Technology.

The following appointments by President Coble were reported; as representative at the inauguration of W. O. Menden- 
hall as President of Whittier College, September 21, 1934, Professor E. R. Hedrick; as additional member of the Committee on the Award of the Cole Prize in Algebra, Professor R. W. Barnard.

On Thursday morning there was a business meeting of the Society. At this meeting on recommendation of the Council, the by-laws were changed so as to assign $\$ 5$ of the dues of each member to the Bulletin.

The titles and cross references to abstracts of the papers read at the sessions follow below. The papers were read as follows: papers numbered 1 to 6 in the Section for Analysis on Tuesday afternoon, Professor G. D. Birkhoff presiding; papers numbered 7 to 10 in the Section for Algebra on Tuesday afternoon, Professor Oystein Ore presiding; papers numbered 11 to 17 in the Section for Analysis on Wednesday morning, Professor Marston Morse presiding; papers 18 to 20 in the Section for Algebra and Number Theory on Wednesday morning, Professor H. W. Brinkmann presiding; papers 21 to 23 on Thursday morning, Professor Virgil Snyder presiding; papers 24 to 37 on Thursday afternoon, Professor Tibor Radó presiding; papers 38 to 66 on Friday morning, Professor Arnold Dresden presiding. Mr. Curtiss was introduced by Professor J. L. Walsh, Mr. Elliott by Professor E. R. C. Miles, Mr. Seale by Professor J. V. Uspensky, Mr. Reingold by Professor I. A. Barnett, Mr. Friedman by Professor B. P. Gill, Mr. Levinson by Professor Norbert Wiener, Mr. Van Schaack by Professor Marston Morse, Dr. Terry by Professor H. R. Brahana. Mr. Trump's paper (number 9) was communicated by Professor M. H. Ingraham. Papers whose abstract numbers are followed by $t$ were read by title.

1. Interpolation in regularly distributed points, by $\mathrm{Mr}$. John Curtiss. (Abstract No. 40-9-263.)

2. On approximation by polynomials to a function analytic in a simply connected region, by Professor O. J. Farrell. (Abstract No. 40-9-265.)

3. Analytic approximations to manifolds, by Dr. Hassler Whitney. (Abstract No. 40-9-293.)

4. On the zeros of the derivative of a rational function, by Pro. fessor Morris Marden. (Abstract No. 40-9-283.) 
5. A mixed boundary-value problem for the heat equation, by Mr. E. R. Elliott. (Abstract No. 40-9-264-t.)

6. Integration of functions with values in a Banach space, by Mr. Garrett Birkhoff. (Abstract No. 40-9-299.)

7. Metabelian groups and pencils of bilinear forms, by Professor H. R. Brahana. (Abstract No. 40-9-261-t.)

8. The non-singular case of the equivalence of pairs of Hermitian matrices, by Professor M. H. Ingraham. (Abstract No. 40-7-242.)

9. On a reduction of matrices by the group of matrices commutative with a given matrix, by Mr. P. L. Trump. (Abstract No. 40-7-251.)

10. A simple proof of Minkowski's theorem concerning nonhomogeneous linear forms, by Mr. R. Q. Seale. (Abstract No. 40-9-287-t.)

11. Linear differential equations with almost periodic coefficients, by Dr. R. H. Cameron (National Research Fellow). (Abstract No. 40-5-217.)

12. Seminvariants of a system of linear homogeneous differential equations of the second order, by Mr. Haim Reingold and Professor I. A. Barnett. (Abstract No. 40-7-249.)

13. A priori limitations for solutions of elliptic Monge-Ampère equations, by Dr. Hans Lewy. (Abstract No. 40-9-278.)

14. A singular solution of a functional equation, by Mr. L. B. Robinson. (Abstract No. 40-9-286-t.)

15. An inclusion theorem in the theory of summable series, by Dr. H. L. Garabedian. (Abstract No. 40-7-245-t.)

16. On the nature of the "reflection" in a plane boundary corresponding to the boundary condition $\partial u / \partial n+$ const. $u=0$, by Dr. Hillel Poritsky. (Abstract No. 40-9-305.)

17. The theory of the second variation for the non-parametric problem of Bolza, by Dr. W. T. Reid. (Abstract No. 40-9-306.)

18. On certain rings and differential ideals, by Professor N. H. McCoy. (Abstract No. 40-9-279.)

19. Zeroless solutions of systems of linear equations in a finite field, by Professor B. P. Gill. (Abstract No. 40-9-272.)

20. Sufficient conditions for the solvability of some Pellian equations, by Mr. Bernard Friedman. (Abstract No. 40-9-270.)

21. The inter-deducibility of the new Hilbert-Bernays theory 
and Principia Mathematica, by Professor E. V. Huntington. (Abstract No. 40-7-246.)

22. Foundations of the theory of abstract sets from the standpoint of combinatory logic, by Professor H. B. Curry. (Abstract No. 40-9-262.)

23. On the asymptotic solutions of ordinary differential equations, with reference to the Stokes phenomenon about a singular point, by Professor R. E. Langer. (Abstract No. 40-9-275.)

24. Note on linear operations on functions of bounded variation, by Professor J. J. Gergen. (Abstract No. 40-9-271.)

25. A local solution of the difference equation $\Delta y=f$ and of related equations, by Professor I. M. Sheffer. (Abstract No. 40-9-288.)

26. The problem of Bolza in the calculus of variations in parametric form, by Dr. M. R. Hestenes (National Research Fellow). (Abstract No. 40-9-273.)

27. A note on permutable self-adjoint transformations in Hilbert space, by Dr. E. R. Lorch (National Research Fellow). (Abstract No. 40-7-248.)

28. On the vanishing of a function over an interval, by $\mathrm{Mr}$. Norman Levinson. (Abstract No. 40-9-276.)

29. On properties of regions which persist in the subregions bounded by level curves of the Green's function, by Professor L. R. Ford. (Abstract No. 40-9-267-t.)

30. An operational solution of the Maxwell field equations, by Dr. E. P. Northrop. (Abstract No. 40-9-285.)

31. Sufficient conditions in the problem of Lagrange without assumptions of normalcy, by Professor Marston Morse. (Abstract No. 40-9-303-t.)

32. Convergence properties of Fourier series, by Professor Otto Szász. (Abstract No. 40-9-297-t.)

33. A formula for finding the skewness of the distribution made up of a finite number of samples, by Professor W. D. Baten. (Abstract No. 40-9-298-t.)

34. The fundamental groups of group manifolds, by Professor P. A. Smith. (Abstract No. 40-9-296-t.)

35. The critical point theory under general boundary conditions, by Professor Marston Morse and Mr. G. B. Van Schaack. (Abstract No. 40-9-302-t.)

36. The boundary conditions in the critical point theory, by 
Professor Marston Morse and Mr. G. B. Van Schaack. (Abstract No. 40-9-301-t.)

37. Short proof of Kellogg's lemma, by Professor G. C. Evans. (Abstract No. 40-9-304-t.)

38. On nets of algebraic surfaces, by Professor T. R. Hollcroft. (Abstract No. 40-9-274.)

39. A six-color problem, by Professor Philip Franklin. (Abstract No. 40-9-269.)

40. On certain types of continuous transformations of metric spaces, by Professor W. A. Wilson. (Abstract No. 40-7-252-t.)

41. Some unique separation theorems for graphs, by Dr. Saunders MacLane. (Abstract No. 40-9-280.)

42. On the expansion of harmonic functions in series of harmonic polynomials belonging to a simply connected region, by Professor O. J. Farrell. (Abstract No. 40-9-266-t.)

43. Dynamics of multi-phase commutator motors (preliminary report), by Mr. W. H. Ingram. (Abstract No. 40-7-247-t.)

44. A theorem on the magnitude of Fourier transforms, by $\mathrm{Mr}$. Norman Levinson. (Abstract No. 40-9-277-t.)

45. On the partial derivatives of harmonic functions as functionals of the determining boundaries, by Dr. Mildred M. Sullivan (National Research Fellow). (Abstract No. 40-9-289-t.)

46. On cyclic fields, by Professor A. A. Albert. (Abstract No. 40-9-254-t.)

47. A greatest common divisor process for integers of a quadratic field, by Professor A. A. Albert. (Abstract No. 40-9-255-t.)

48. The principal matrices of a Riemann matrix, by Professor A. A. Albert. (Abstract No. 40-9-256-t.)

49. On the power series for elliptic functions, by Professor E. T. Bell. (Abstract No. 40-7-244-t.)

50. Concerning the order of a linear transformation with coefficients in a $G F(p)$, by Professor H. R. Brahana. (Abstract No. 40-9-260-t.)

51. A classification of finite distributive lattices, by Dr. Saunders MacLane. (Abstract No. 40-9-281-t.)

52. Groups in which the squares of the elements are dihedral groups, by Professor G. A. Miller. (Abstract No. 40-9-284-t.)

53. Abelian subgroups of the I-group of the abelian group of order $p^{n}$ and type 1, 1, . . , by Dr. Henrietta Terry. (Abstract No. 40-9-290-t.) 
54. On the expansion of the remainder in the Newton-Cotes formula, by Professor J. V. Uspensky. (Abstract No. 40-9-291-t.)

55. Irreducibility of polynomials of degree $n$ which assume the same value $n$ times, by Professor Louis Weisner. (Abstract No. 40-9-292-t.)

56. On the abstract properties of linear dependence, by Dr. Hassler Whitney. (Abstract No. 40-9-294-t.)

57. Multiply connected sets, by Dr. R.-E. Basye. (Abstract No. 40-9-257-t.)

58. Transfinite extensions of the Jordan-Hölder theorem, by Mr. Garrett Birkhoff. (Abstract No. 40-5-218-t.)

59. An application of a theorem of $K$. Gödel, by Dr. L. M. Blumenthal (National Research Fellow). (Abstract No. 40-9258-t.)

60. A decomposition of the spherical surface $S_{2, r}$ by means of tetrahedral quadruples, by Dr. L. M. Blumenthal (National Research Fellow). (Abstract No. 40-9-259-t.)

61. On Minkowski's definition of length and area, by Professor Philip Franklin. (Abstract No. 40-9-268-t.)

62. A projective generalization of metrically defined associate surfaces, by Professor M. L. MacQueen. (Abstract No. 40-9282-t.)

63. Prime ends and indecomposability, by Dr. N. E. Rutt. (Abstract No. 40-7-243-t.)

64. The analysis of certain curves by means of derived local separating points, by Dr. G. E. Schweigert. (Abstract No. 407-250-t.)

65. On the imbedding of metric sets in euclidean space, by Professor W. A. Wilson. (Abstract No. 40-7-253-t.)

66. The equation of Izumi and a contour problem, by Mr. L. B. Robinson. (Abstract No. 40-9-295-t.)

J. R. KLINE, Associate Secretary 